\title{
剪切带的成分变异及体积亏损 以河台剪切带为例*
}

\author{
钟增球 游振东
}

(中国地质大学岩石数研室, 武汉 430074)

\section{关钺词 河台然切带 成分变异 体积亏损 流体/岩石比}

作为地壳中的缺陷, 尊切带中存在着热、力、化学和流体之间的耦合作用. 应变局部化和 力学失稳引起的化学不平衡和组分的迁移, 使化学成分重新调整. 关于剪切带中元素的富集 与亏损, 存在不同的解释 ${ }^{11 \sim 4}$, 但已较普遍认为, 某些元素, 尤其是一些活动性较小的高场强元 素 (如 Ti, P, Zr, Y, V 等) 的富集, 很可能与剪切带的体积亏损有关. 剪切带的成分变异及体 积亏损, 除了与应变有关外, 流体的流动是一个极为重要的因素.

本文拟以广东河台尊切带为例, 阐明剪切带中化学成分的变异情况及其与体积亏损和流 体作用之间的关系.

\section{1 河台剪切带的地质特征}

河台剪切带为云开隆起北端一条北东向韧性 - 脆韧性剪切带, 也是典型的含金尊切带之 一. 该剪切带发育于不同地质体或不同岩性界面间, 如加里东混合岩与花岗岩或混合岩与云 开群变质岩系之间等, 宽约 $2.5 \mathrm{~km}$, 长约 $30 \mathrm{~km}$, 糜棱面理一般向北西陡倾, 倾角 $60^{\circ} \sim 80^{\circ}$, 近 水平线理发育, 为右行走滑型剪切带. 带内发育了数条糜棱岩带, 宽数厘米至数十厘米不 等, 长数十至上千米, 糜棱岩分带明显, 包括初糜棱岩、糜棱岩和千糜棱岩等, 其中 S-C 构造, $C^{\prime}$ 面理和云母鱼构造发育, 多属半塑性糜棱岩[?, 并常有假玄武玻璃与之伴生. 据糜棱岩的性质 及其矿物共生和显微构造组合等判断, 河台剪切带形成于半塑性域, 或相当于绿片岩相环 境.

\section{2 成分变异及体积亏损}

于云西矿区对河台䙷切带具代表性的一条糜棱岩带沿其横剖面作岩石常量元素和微量元 素分析, 其结果如表 1 所示. 所分析的原岩为轻微混合岩化的二云石英片岩, 主要矿物组成为 石英 + 黑云母 + 白云母 + 酸性斜长石, 糜棱岩化后基质矿物组合为石英 + 钠长石 + 白云母 + 绿泥石, 为了检验其原岩的一致性, 对原岩和糜棱岩分别作了稀土分析 (图 1). 结果表明, 片 岩、糜棱岩和千糜岩都有着极为相似的稀土配分型式, 虽然随着糜棱岩化的增强, 稀土丰度有

1994-08-01 收稿, 1994-12-21 收修改稿

*地质矿产部科技攻关资助项目 


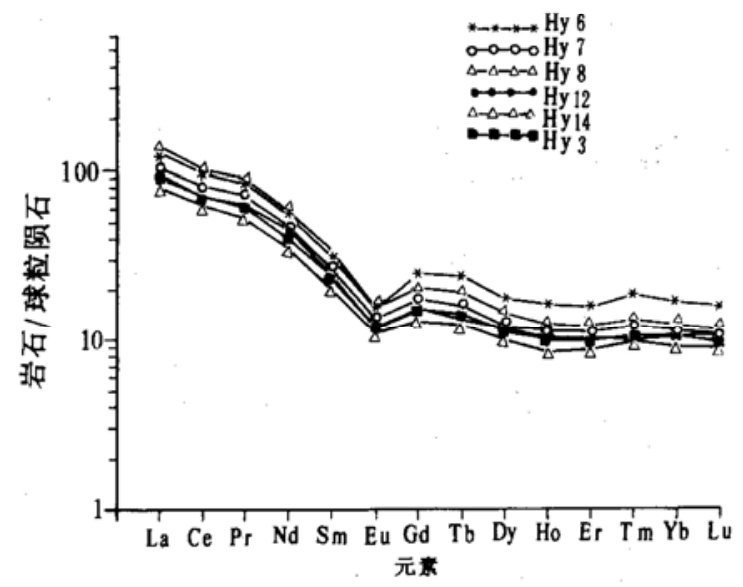

图 1 河台剪切带岩石稀土配分模式 Hy 3 为混合岩化片岩, 其余同表 1
所增加, $\delta E u$ 值略有减小, 但配分型式不 变, 说明了其原岩是一致的.

由表 1 可看出, 从混合岩化片岩至糜棱 岩再至千糜岩, $\mathrm{Al}_{2} \mathrm{O}_{3}, \mathrm{~K}_{2} \mathrm{O}, \mathrm{CaO}, \mathrm{Fe}_{2} \mathrm{O}_{3}$, $\mathrm{TiO}_{2}, \mathrm{MnO}, \mathrm{P}_{2} \mathrm{O}_{5}$ 和 $\mathrm{Y}, \mathrm{Zr}, \mathrm{Cr}$ 等呈增长趋 势, 而 $\mathrm{SiO}_{2}$ 和 $\mathrm{Na}_{2} \mathrm{O}$ 等则有所减少. 对于这 种相对的变化, 可以有两种解释: 一是某些 元素如 $\mathrm{Al}, \mathrm{Ti}, \mathrm{Zr}, \mathrm{Y}, \mathrm{P}$ 的富集, 纯粹是流 体带来的, 这种解释的前提是上述元素都 是活动的. 二是某些元素, 尤其是一些高 场强元素的相对富集, 与体积亏损有关.

显然后一种解释较为合理.

表 1 河台剪切带岩石化学成分分析结果表 (常量元素的质量分数 $/ \%$, 微量元素为 $\left.\times 10^{-6}\right)^{\mathrm{a})}$

\begin{tabular}{|c|c|c|c|c|c|c|c|c|c|c|c|c|c|c|}
\hline 岩柱 & 样品 & $\mathrm{SiO}_{2}$ & $\mathrm{TiO}_{2}$ & $\mathrm{Al}_{2} \mathrm{O}_{3}$ & $\mathrm{Fe}_{2} \mathrm{O}_{3}$ & $\mathrm{FeO}$ & $\mathrm{MnO}$ & $\mathrm{MgO}$ & $\mathrm{CaO}$ & $\mathrm{Na}_{2} \mathrm{O}$ & $\mathrm{K}_{2} \mathrm{O}$ & $\mathrm{P}_{2} \mathrm{O}_{5}$ & $\mathrm{H}_{2} \mathrm{O}$ & $\mathrm{CO}_{2}$ \\
\hline $\begin{array}{l}\text { 混合岩 } \\
\text { 化片岩 }\end{array}$ & $\begin{array}{l}3 \text { 个 } \\
\text { 平均 }\end{array}$ & 73.59 & 0.45 & 13.14 & 0.48 & 2.88 & 0.01 & 1.34 & 0.69 & 1.98 & 3.30 & 0.17 & & \\
\hline \multirow{4}{*}{ 糜棱岩 } & $\mathrm{Hy} 7$ & 69.87 & 0.62 & 13.93 & 2.46 & 2.23 & 0.04 & 1.61 & 0.51 & 1.10 & 3.64 & 0.17 & 2.56 & 0.76 \\
\hline & Hy8 & 70.50 & 0.45 & 14.78 & 2.57 & 0.34 & 0.07 & 0.87 & 0.88 & 1.96 & 3.72 & 0.22 & 2.70 & 0.66 \\
\hline & Hy12 & 70.05 & 0.54 & 13.46 & 2.89 & 1.11 & 0.06 & 1.32 & 1.38 & 1.38 & 3.92 & 0.16 & 2.74 & 1.03 \\
\hline & 平均 & 70.14 & 0.54 & 14.06 & 2.64 & 1.23 & 0.06 & 1.21 & 0.92 & 1.48 & 3.76 & 0.18 & 2.67 & 0.82 \\
\hline \multirow{3}{*}{ 千糜岩 } & Hy6 & 63.92 & 0.62 & 16.73 & 2.74 & 2.74 & 0.07 & 2.05 & 0.74 & 0.84 & 4.90 & 0.27 & 3.24 & 0.84 \\
\hline & Hy14 & 62.64 & 0.65 & 17.79 & 2.25 & 1.05 & 0.16 & 1.53 & 1.89 & 0.44 & 5.72 & 0.20 & 2.81 & 2.71 \\
\hline & 平均 & 63.28 & 0.64 & 17.26 & 2.50 & 1.90 & 0.12 & 1.79 & 1.32 & 0.64 & 5.31 & 0.24 & 3.03 & 1.78 \\
\hline 岩柱 & 样品 & & $\mathrm{Cr}$ & & $\mathrm{Ni}$ & & Co & & $Y$ & $\mathrm{Zr}$ & & $\mathrm{Cu}$ & & \\
\hline $\begin{array}{l}\text { 混合岩 } \\
\text { 化片岩 }\end{array}$ & $\begin{array}{l}8 \text { 个 } \\
\text { 平均 } \\
\end{array}$ & & 56 & & 32 & & 14 & & 4 & 186 & & 85 & & \\
\hline \multirow{4}{*}{ 糜棱岩 } & Hy6 & & 77 & & 31 & & 14 & & 5 & 210 & & 21 & & \\
\hline & Hy8 & & 47 & & 24 & & 12 & & 6 & 145 & & 13 & & \\
\hline & Hy12 & & 58 & & 26 & & 13 & & 5 & 236 & & 25 & & \\
\hline & 平均 & & 61 & & 27 & & 13 & & 5 & 197 & & 20 & & \\
\hline \multirow{3}{*}{ 千糜岩 } & Hy6 & & 81 & & 36 & & 14 & & 8 & 198 & & 46 & & \\
\hline & Hy14 & & 81 & & 27 & & 11 & & 9 & 188 & & 744 & & \\
\hline & 平均 & & 81 & & - $\quad 32$ & & 13 & & 9 & 193 & & 395 & & \\
\hline
\end{tabular}

a) 湖北地质测试研究所测试, 混合岩化片岩部分引自符力奋等 (1988)河台金矿区变质作用与成矿作用专题研究报告

据表 1 中化学分析结果, 应用 O'Hara(1988) 等归纳的方法, 作出了等比线图 (Isocon diagram) 如图 2 所示. 图中 $\mathrm{Al}, \mathrm{Ti}, \mathrm{Y}, \mathrm{P}, \mathrm{Zr}$ 等不活动组分基本位于等比线上, 它们在糜棱岩 化前后没有或基本没有迁移,其相对富集是由于体积亏损所造成的. 等比线以下的组分有所 失, 其中 $\mathrm{Si}$ 和 $\mathrm{Na}$ 被带出较多; 而等比线以上的组分则有所得, 如千糜岩中的 $\mathrm{K}_{2} \mathrm{O}$ 明显富集, 是剪切活动过程中被带人的组分. 这些被带人或带出的组分, 大多是一些活动组分. 


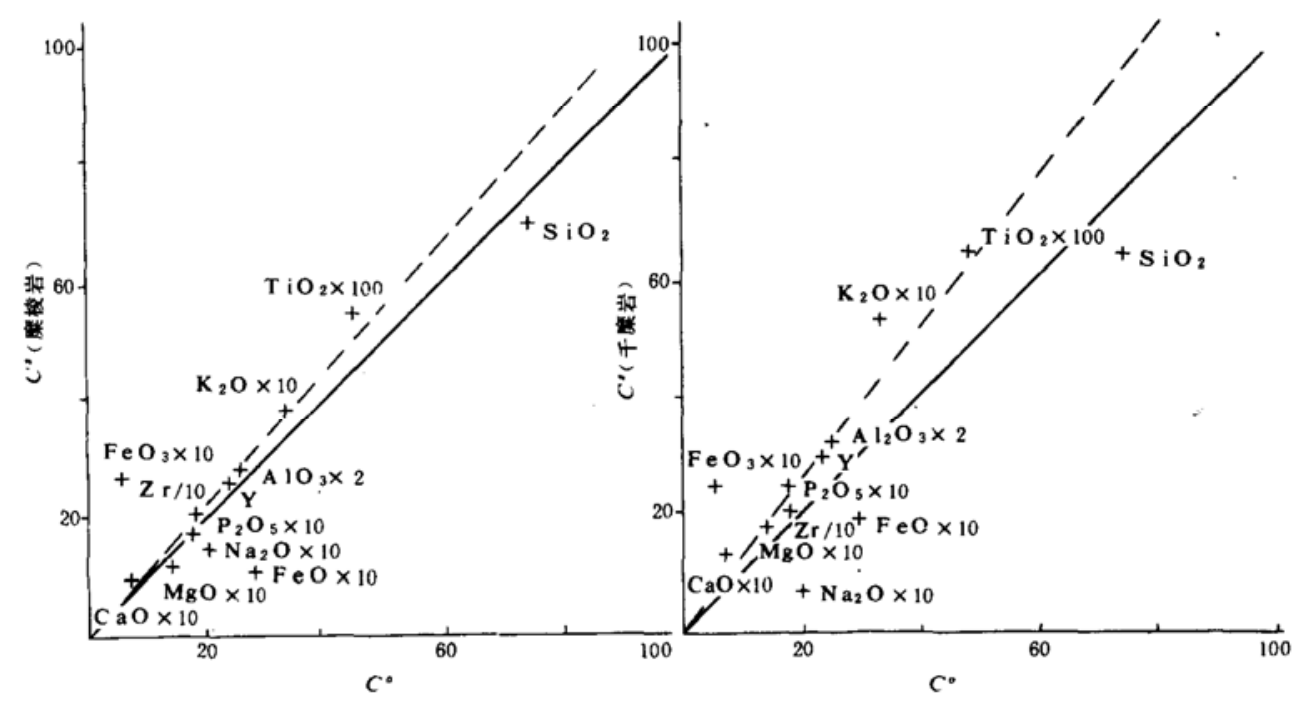

图 2 化学成分变异等比线图

根据体积亏损公式 $C^{s} / C^{o}=1 /(1-V)\left(O^{\prime} H a r a, 1988\right)$, 求出糜棱岩和千糜岩的体积亏损率 $(V)$ 分别为 $11 \%$ 和 $28 \%\left(C^{s} / C^{\circ}\right.$ 为图 2 中等比线的斜率 $)$.

\section{3 质量平衡和流体/岩石比}

根据 Gresens(1967) 提出的公式, 可算出糜棱岩化后岩石中各组分 $(n)$ 的得失率 $(X n)$

$$
X n=100\left[F_{\mathrm{v}}\left(\rho_{s} / \rho_{0}\right) C_{n}^{s}-C_{n}^{0}\right],
$$

其中 $F_{\mathrm{v}}$ 为体积因子, 即体积亏损后的体积与原体积之比; $\rho_{0}$ 和 $\rho_{s}$ 分别为糜棱岩化前后岩石的 密度, $C_{n}^{0}$ 和 $C_{n}^{s}$ 分别为 $n$ 组分糜棱岩化前后的质量分数 $/ \%$.

已测得混合岩化片岩, 糜棱岩和千糜岩的密度分别为 $2.68,2.71$ 和 2.71 , 以原岩重 $100 \mathrm{~g}$ 为 参考值, 可得出下列质量平衡方程.

对于糜棱岩为:

$$
\begin{aligned}
& 100 \mathrm{~g} \text { 片岩 }-10.47 \mathrm{gSiO}_{2}-0.49 \mathrm{gAl}_{2} \mathrm{O}_{3}-1.77 \mathrm{gFeO}-0.25 \mathrm{gMgO}-0.65 \mathrm{gNa}_{2} \mathrm{O} \\
& =0.04 \mathrm{gTiO}_{2}+1.90 \mathrm{gFe}_{2} \mathrm{O}_{3}+0.04 \mathrm{gMnO}^{2}+0.14 \mathrm{gCaO}+0.08 \mathrm{gK}_{2} \mathrm{O}+88.57 \mathrm{~g} \text { 糜棱岩 }
\end{aligned}
$$

对于千糜岩为:

$$
\begin{aligned}
& 100 \mathrm{~g} \text { 片岩 }-27.52 \mathrm{gSiO}_{2}-0.57 \mathrm{gAl}_{2} \mathrm{O}_{3}-1.50 \mathrm{gFeO}-0.04 \mathrm{gMgO}-1.33 \mathrm{gK}_{2} \mathrm{O} \\
& =0.01 \mathrm{gTiO}_{2}+1.34 \mathrm{gFe}_{2} \mathrm{O}_{3}+0.08 \mathrm{gMnO}+0.27 \mathrm{gCaO}+0.57 \mathrm{~K}_{2} \mathrm{O}+71.31 \mathrm{~g} \text { 千糜岩 }
\end{aligned}
$$

上述质量平衡方程所反映的糜棱岩和千糜岩中各组分的得失率, 与上述等比线图所示的 结果一致.

较大的体积亏损, 以及 $\mathrm{SiO}_{2}$ 的较大量流失, 意味着尊切带中有着大量的渗透流体, 从 $\mathrm{SiO}_{2}$ 的亏损, 可算出流体/岩石比 $(N)$

$$
\left.N=L_{\mathrm{Si}} / C_{\mathrm{Si}}^{\mathrm{f}}(1-S) \quad \text { (据 } \mathrm{O}^{\prime} \mathrm{Hara}^{[\natural}\right) \text {, }
$$

式中 $L_{\mathrm{Si}}$ 为 $\mathrm{SiO}_{2}$ 在糜棱岩或千糜岩中的亏损, $C_{\mathrm{Si}}^{\mathrm{f}}$ 为 $\mathrm{SiO}_{2}$ 在流体中的溶解度, $S$ 代表 $\mathrm{SiO}_{2}$ 在流 体中的饱和度. 据研究, 在 $400{ }^{\circ} \mathrm{C}$ 和 $400 \mathrm{MPa}$ 的条件下 (与本剪切带的形成条件相当), $\mathrm{SiO}_{2}$ 在 水中的溶解度为 $5 \mathrm{~g} / \mathrm{kg}$ (Holland and Malinin, 1979); 另外一般假定 $\mathrm{SiO}_{2}$ 的饱和度在 $50 \% \sim 90 \%$ 


\section{之间, 则依据上述公式}

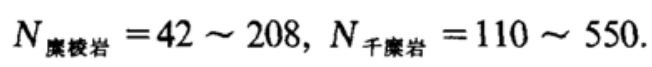

如此大量的渗透流体, 对剪切带的流变行为、化学行为和成矿作用肯定有着深刻的影响.

\section{参考文献}

1 O'Hara K. Fluid flow and volume loss during mylonitization: an origin for phyllonite in an overthrust setting, North Carolina, USA. Tectonophysics, 1988, 156: $21 \sim 36$

2 Selverstone J, Morteani G, Staude J M. Fluid channeling during ductile shearing: transformation of granodiorite into aluminous schist in the Tauem Window, Eastern Alps. J Metamorphic Geol, 1991, 9:419 431

3 Losh S. Fluid-rock interaction in an evolving ductile shear zone and across the brittle-ductile transition ontral Pyrenees, France. Am J Sci, 1989, 289: $600 \sim 648$

4 Newman J, Mitra G. Lateral variations in mylonite zone thikness as influenced by fluid-rock interactions, Linville Falls, North Carolina. J Struc Geol, 1993, 15: $849 \sim 863$

5 钟增球. 构造岩研究的新进展. 地学前缘, 1994, (1-2): $162 \sim 169$

6 O'Hara K, Blackburn W H. Volume-loss model for trace-element enrichments in mylonites. Geology, 1989, 17: $524 \sim 527$ 